three": the rule states that if none of $n$ patients shows the event about which we are concerned, we can be $95 \%$ confident that the chance of this event occurring is at most three in $n$-that is, $3 / n$. In other words the upper $95 \%$ confidence limit of a $0 / n$ rate is $3 / n$. Combining our observations with those of $\mathrm{Dr}$ Hosie and Dr Hosie the risk of hydralazine induced lupus when the daily dose is limited to $100 \mathrm{mg}$ in men and $50 \mathrm{mg}$ in women is likely to be at most $3 / 176-1.7 \%$.

This figure suggests to us that these dose limits for hydralazine are acceptably safe. As we stated in our original article, however, the antihypertensive effect of such low dose hydralazine will often prove unsatisfactory.

LAWRENCE E RAMSAY HaMish A CAMERoN

University Department of Therapeutics, Royal Hallamshire Hospital, Sheffield S10 2JF

1 Hanley JA, Lippman-Hand A. If nothing goes wrong, is everything all right ? Interp
tors. $f A M A 1983 ; \mathbf{2 4 9}: 1743-5$.

\section{Urinary tract infection in children}

SIR,-Dr Helen L A Houston (22 September p 766) comments that the study of Dr W Mckerrow and others (4 August, p 299) was of a highly selected group of children and that it is hardly scientific to extrapolate the results of such hospital studies based on selected high risk children to the genera population. She goes on to comment that a large prospective study of the condition in general practice is needed to allay fears that many children will continue to be exposed to radiological and urological examination.

In a recent study with both general practitioner and non-specialist paediatricians in the South Eas Thames region we sought to test opinions on referral policy and investigation protocol in firs time childhood urinary tract infection. ${ }^{1}$ We showed that general practitioners are still divided over the issues of referral after proved first time urinary tract infection and whether to institute identical management for both girls and boys. All the paediatricians considered an intravenous pyelogram as the only first line radiographic investigation of the condition; only seven of the 20 would consider micturating cystography in a $2 \frac{1}{2}$ year old boy with urinary tract infection, and none would contemplate this test for an 8 year old girl.

In Medway health district during the year $1980-3,107$ boys and 169 girls were referred to paediatric outpatients for investigation of urinar tract infections. This is a general departmen located on one site and does not receive referrals from outside the district. Eighty per cent wer referred after what was presumed to be their firs infection. All had intravenous pyelograms, and $22 / 159$ were abnormal among the girls and $18 / 96$ among the boys (not all records could be traced). The most common abnormalities were pelviureteric junction obstruction and bifid drainage systems in boys and vesicoureteric reflux with renal scars in girls.

Excluding neonates, whose referral is likely to be from hospital, the rest were referred from general practice (not always with a correct diagnosis). The proportion of children with urinary tract abnormality detected by intravenous pyelogram after first time urinary tract infection is lower than in surveys from specialised centres such a that of Dr McKerrow and others. This we expected, yet it is still high enough to suggest an intravenous pyelogram ought to be performed on every child with a proved urinary tract infection.

These data illustrate the point made in the concluding paragraph of our recent study that in any health district general practitioners and consultants should together be able to formulate a practical management policy for childhood urinary tract infection based on local data and hence relevant to that population. ${ }^{1}$ Using the incidence rate from our study we expect about 50 boys and 90 girls aged 1 year to 10 years to be referred in the Medway health district in any one year. Over the past four years the actual numbers have been about half that.

In the light of local data present policy in Medway has been amended to recommend referral of any child with proved urinary tract infection. Plans enabling general practitioners to order intravenous pyelograms direct for children meeting the agreed criteria with paediatric follow up of abnormal results are well advanced. We expect that children will then be followed up on a shared care basis.

In the absence of other widely available techniques for identifying children at risk after urinary tract infection it is difficult to imagine how a prospective longitudinal study from general practice is going to shed light on "best current management" without recourse to radiographic investigation of some sort. Perhaps the Medway data points to a middle road between the thorough radiological and urological investigation advocated by $\mathrm{Dr}$ McKerrow and others and Dr Houston's suggestion that many normal children are being exposed to possibly hazardous investigations.

A M Dighe

Higham, Kent

1 Dighe AM, Grace JF. General practice management of Pract $1984 ; \mathbf{3 4}: 324-7$.

\section{Menopause}

Sir,-Dr Jean Coope (6 October, p 888) provides us with cogent reasons for the low percentage of menopausal women (less than $2 \%$ of her menopausal patients) who are prepared to take hormone replacement treatment. The fear of cancer initially dissuaded $\mathrm{Dr}$ Coope from taking hormone replacement treatment for long, but she readily resumed treatment when she discovered that the grim forebodings of the prophets of doom had been false.

There are those among us who say that hormone replacement treatment is a natural way of treating ovarian hormone deficiency, but how can we reconcile this natural form of treatment with the necessity to have frequent pelvic examinations and uterine curettage. Little wonder that few menopausal women are prepared to be unnaturally assaulted at indecently frequent intervals and prefer instead to put up with their menopausal symptoms. With these preconditions imposed on potential recipients of hormone replacement treatment those women without any menopausal symptoms at all would have to be masochistic to agree to take such pills for the possible prevention of osteoporosis. This poses a serious stumbling block for those of us who are attempting to reduce the prevalence of osteoporosis among aging women, especially since oestrogen treatment is the most effective way of preventing it. ${ }^{1}$

Those with a research interest in the menopause have provided us with scientific guidance on the real risks of genital cancer in women on hormone replacement treatment. ${ }^{2}$ They have produced no good evidence that intermittent oestrogen treatment (with a minimum of seven days' progestogen treatment on the oestrogen free days) is associated with any real risk of genital cancer, and therefore uterine curettage is essential only in those women with an unscheduled uterine bleed. In my experience unscheduled bleeds are uncommon where a daily dosage of 10-20 $\mu \mathrm{g}$ of ethinyl oestradiol is prescribed and either $350 \mu \mathrm{g}$ of norethisterone or $500 \mu \mathrm{g}$ of ethynodiol diacetate is taken daily on the seven oestrogen free days of the month.

If we accept these assertions then it really is time that we stopped frightening women with the imaginary evils of hormone replacement treatment and started to woo them with the possible long term benefits.

J M AitKeN

Essex County Hospital,

Essex CO3 3N

1 Aitken M. Whither osteoporosis. In: Osteoporosi in clinical practice. Bristol: John Wright, 1984 $122-6$. 2 Studd J. Guidelines for community menopausal clinics. Br Med f 1983;287:286-7.

\section{Night workload in one health district}

SIR,-Dr J D Budd and Dr D N H Greig (20 October, $p$ 1074) highlight the gap between GPs who want to do their own on call work and those who prefer mostly to use deputising services, which boils down to a choice between the rare night frequently disturbed and more frequent nights on call when rarely disturbed. How individuals cope and which they prefer is, I believe, dependent on personality. Dr N W S Hester 20 October, p 1074) has not acknowledged that the night visiting rate is not the whole story, and many have bad nights on call even when not disturbed. By allowing doctors to cover for their own patients until $11 \mathrm{pm}$ and then have a good night's sleep, the scheme I suggested aims at bridging this divide (15 September, p 663).

My conclusions have been criticised by Dr Hester for not producing enough work. He visualises "one doctor 'on the road' each night impatiently waiting for the next call to come in." Dr D P M Archer's (20 October, $\mathrm{p}$ 1073) worst nightmare is that up to 16 patients may require attention $5 \%$ of the time (his calculation), and he thus thinks there is too much work. He forgets that there are two doctors available to see patients, and I believe that even if the rate were doubled or tripled it could still easily be coped with by the two GPs. His point that if each GP forgot to file one night visit form annually the figures would be "very different" is not correct. This would add just one visit to every fourth night-still hardly taxing.

Although not included in the original paper, my data confirm the low attendance at casualty between $11 \mathrm{pm}$ and $7 \mathrm{am}$. In the same three month period studied 386 patients attended, producing 123 admissions (maximum in one night 13 attendances, four admissions) many of which were GP referrals not seen by the casualty officer, but recorded and included in the night visit form returns. Thus the total number of doctor-patient contacts in the whole health district between $11 \mathrm{pm}$ and 7 am for this period was 685 (386 plus 299 night visit forms). (In practice it was less because, as explained, some admissions through casualty referred by GPs would be counted twice.) This still allows an average of over three doctors available for each patient needing attention. In my experience as a former 